\title{
Effect of the Imperfection of Open-End Yarn (Thin, Thick, and Nep Place) on Air Permeability of Plain Woven Fabric
}

\author{
Erkihun Zelalem Liyew (D) \\ Ethiopian Institute of Textile and Fashion Technology (EiTEX), Bahir Dar University, Bahir Dar, Ethiopia \\ Correspondence should be addressed to Erkihun Zelalem Liyew; erkihunz09@gmail.com
}

Received 18 September 2021; Revised 13 November 2021; Accepted 18 January 2022; Published 18 February 2022

Academic Editor: Homayoon Oraizi

Copyright (c) 2022 Erkihun Zelalem Liyew. This is an open access article distributed under the Creative Commons Attribution License, which permits unrestricted use, distribution, and reproduction in any medium, provided the original work is properly cited.

\begin{abstract}
Wearing clothes is an intermediate channel by exchange of air released from human bodies and environments to bring breathing stability and to control body temperature. Air permeability is an expression describing the properties of a fabric that permit the passage of air through the fabric's interstices. It has been found that there are many factors that can affect the air permeability of a fabric comfort. Several early studies of air permeability of different materials showed that different factors affect air permeability and breathability of fabrics, and some of them are imperfections of yarns (thick, thin, and nep place) which are introduced on the surface of the fabric that originated from the appearance of the yarn. In this experiment, the yarn and fabric samples are collected from five different spinning mills which have an identical warp yarn linear density of $20 \mathrm{Ne}$ regardless of the weft linear density, and the fabric was constructed from those selected yarns by using the thread set of 28 ends per centimeter and 20 picks per centimeter. The experiment was conducted by measuring the imperfection of each code of yarn on USTER statistics and air permeability of the fabric with respect to the thin, thick, and nep place $/ \mathrm{km}$ of the yarn and fabric cover. The impacts of each factor were analyzed, and the relationships of each parameter were stated on the graph. The results were discussed by using the design of the experiment by quadratic and linear models to the response of air permeability and fabric cover, respectively, and the results showed that there is a direct impact of thin, thick, and neps of the yarn on the ability of the fabric to permeate air.
\end{abstract}

\section{Introduction}

Clothes are used to maintain and protect body temperature. In order to balance high heat that surrounds the body, garment permits sweat to evaporate (cooling off by perspiration). When humans are under high temperatures or do physical exercises, the fluctuation of fabric during movement creates air streams, which increase perspiration and cooling off. Body temperature is kept cold by the fabric layer that provides insulation a little. For these reasons, clothing comfort is of great importance from the point of a user. Clothing comfort can be examined in three different categories such as psychological, handle, and thermal comfort. Psychological comfort can be explained with the user influenced by the fashion and culture. Fabric handle is defined basically as the feeling when the thumb and index finger touch the fabric. Thermal comfort is a phenomenon, which is close to thermal and liquid or air permeability properties of fabrics [1]. The human body produces moisture in the form of perspiration; it should be removed from to the surface of the skin and from the inside of the fabric surface. The fabrics should allow moisture in the form of sensible and insensible preparations to be transmitted from the body to the atmosphere in order to cool the body. After the body has stopped the sweating, the textile fabric should release in the atmosphere. There are different research works which are carried out to improve the transportation properties of fabrics such as air, water, or thermal [2].

Air permeability is an important factor in the performance of textile materials such as gas filter, fabrics for air bags, clothing, mosquito netting, parachutes, sails, tentage, and vacuum cleaners. It can also be used to provide an indication of the breathability of weather-resistant and rainproof fabrics. The end-use and performance 
requirements of woven fabrics are strongly related to their cover factors (CFs) or, in opposite terms, to their porosity and permeability [3-5]. The air permeability of the fabric is influenced by different factors, such as the number of warp and weft per centimeter or inch, fabric design, fabric structure, yarn twist, yarn appearance, imperfection, the size of yarn, yarn structure, and fabric finishing. Therefore, to investigate the relationship of all fabric parameters with air permeability is difficult.

In this paper, those parameters are limited to show the effect of imperfections (thin place, thick place, and neps) on the fabric air permeability based on the properties of the yarn which include the irregularity (U\%), coefficient of mass variation $(\mathrm{CVm} \%)$, number of thin places/ $\mathrm{km}(-50 \%)$, thick places $/ \mathrm{km}(+50 \%)$, and neps $/ \mathrm{km}(+280 \%)$ drawn from five spinning mills with similar yarn linear density.

1.1. Air Permeability. The void volume in woven textile fabrics causes air permeability. The air permeability of the textile is determined by the rate of air flow through the material under a differential pressure between the two fabric surfaces $[6,7]$.

1.2. Cover Factor of the Fabric. Cover factor (CF) is defined as the area of yarn in the solid unit cell rectangle [8]. The coefficient of CF is the characterization of the degree of area covered by the threads in the fabric [9]. It can be written as

$$
\text { cover factor }(\mathrm{CF})=\frac{\text { area covered by yarn }}{\text { whole fabric area }} \text {. }
$$

The cover factor of the fabric is the sum of the coverage of the warp and weft yarns. According to different literature studies, the total fabric cover (TFC) has to be

$$
\mathrm{TFC}=\mathrm{D} 1 \mathrm{~N} 1+\mathrm{D} 2 \mathrm{~N} 2-(\mathrm{D} 1 \mathrm{~N} 1 \times \mathrm{D} 2 \mathrm{~N} 2),
$$

where TFC is the total fabric cover, $D_{1}$ is the warp yarn diameter in $\mathrm{cm}, D_{2}$ is the weft yarn diameter in $\mathrm{cm}, N_{1}$ is the warp yarn density (threads/cm), and $N_{2}$ is the weft yarn density (threads $/ \mathrm{cm}$ ) as illustrated in Figure 1.

The diameter of the yarn is estimated based on the linear density of the yarn and its fiber density as follows:

$$
D=4.44 \times 10^{-3} \frac{\sqrt{T_{\text {tex }}}}{\rho},
$$

where $D$ is the diameter of the yarn in $\mathrm{cm}, T_{e x}$ is the linear density of the yarn, and $\rho$ is the fiber density in $\mathrm{g} / \mathrm{cm}^{3}$. The density of the cotton fiber is $1.54 \mathrm{~g} / \mathrm{cm}^{3}$.

1.3. Thin and Thick Places. Together with the impairment of the optical appearance of the textile surface, the number of thin and thick places is important information on the condition of the raw material and/or manufacturing process. An increase in the number of thin places does not necessarily mean that the number of machine standstills increases accordingly during weaving and knitting with this yarn: in many cases, thin places indicate larger yarn twists. This

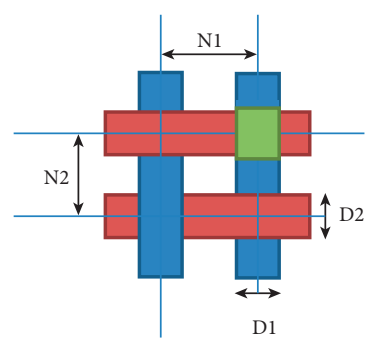

$$
\begin{aligned}
& \square \text { Areas cover by warp yarn } \\
& \text { Areas cover by weft yarn } \\
& \text { Areas cover by warp \& weft yarn }
\end{aligned}
$$

FIGURE 1: Interlacement of the warp and weft yarn.

means that the yarn tensile strength must not necessarily decrease proportional to the reduction in the fiber count [10].

1.4. Neps. Apart from the strong influence on the optical appearance of textile surface structures, neps from a certain size upwards also lead to problems in the knitting machine sector. Not only the size but also the number of neps are decisive criteria as to whether the yarn is useable or not. Neps in the raw material are mainly foreign bodies such as, for example, shell or plant residues, whereas neps in production are created during the spinning process through unsuitable machine settings and a bad ambient climate [11].

\section{Materials and Methods}

2.1. Materials. The woven fabric is constructed from the rotor yarn which has the warp density of $28 \mathrm{ends} / \mathrm{cm}$, and the weft density is 20 picks $/ \mathrm{cm}$. The fabric is produced from different codes of yarn (Codes A, B, C, D, and E) with a similar linear density and thread set. Figure 2 shows that a fabric which is constructed from $100 \%$ cotton open-end yarn and drawn from five spinning mills has a similar number of warp and weft densities in centimeter and also has a similar linear density of warp yarn $20 \mathrm{Ne}$ regardless of weft yarn counts and its imperfection. Both samples which are yarn and fabric were used, and the tests were conducted based on the selected properties of both samples; in fact, these cause highly influential impacts on the ability of fabric air permeability. The reasons for testing of the yarn properties are direct impact on the porosity and coverage of the fabric. To test the imperfection of the yarn is very important to identify the passage of air through the surface of the fabric.

2.2. Sampling and Experimental Design. The $100 \%$ cotton open-end yarn was collected from five different spinning mills which has a similar count of $20 \mathrm{Ne}$, and the yarn was selected randomly from the chase cone, and the fabric was collected from those mills which was constructed by using those yarns regardless of the weft yarn properties and maintained its environmental condition as per the ISO 139 standard. The experiments were done by taking samples of yarn and fabric from different mills with a similar yarn 

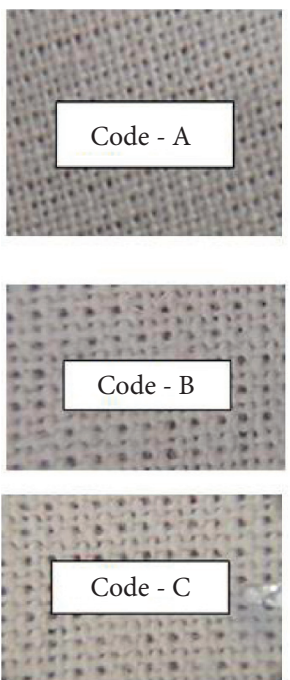
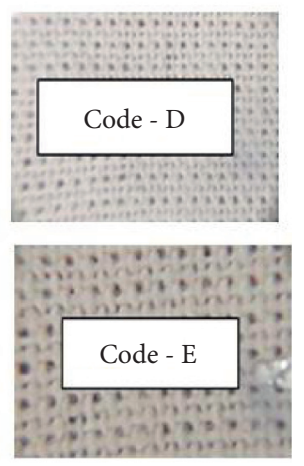

Figure 2: Fabric sample.

density, and the number of tests is listed in Table 1 based on its parameter.

2.3. Equipment. The yarn and the fabric properties were tested by using the following equipment. The tests followed the standards of ASTM D1425, ASTM D737, and ES ISO 3801, respectively, as illustrated in Figure 3.

2.4. Data Analyzed. The woven fabric which was constructed from $100 \%$ cotton open-end yarn and the properties of the yarn were analyzed by USTER 5 statistical analysis, the comparison between them was differentiated by using SPSS software of ANOVA test, and the correlation of the imperfection and air permeability was analyzed by using the design of experiment (DOE) and Excel software.

\section{Results and Discussion}

The USTER statistics of each yarn of irregularity (U\%), coefficient of variation in mass $(\mathrm{CVm} \%)$, thin places $/ \mathrm{km}$ $(-50 \%)$, thick places $/ \mathrm{km}(+50 \%)$, neps $/ \mathrm{km}(+280 \%)$, and hairiness are measured as illustrated in Table 2, and it has a different value of each yarn at the level of imperfection. As shown in Table 3, the strength of the yarn was tested on the universal yarn strength tester by using $50 \mathrm{~cm}$ dimension, the speed of the clump was $120 \mathrm{~mm} / \mathrm{min}$, and the calculated diameter of each yarn was computed based on equation (3) as presented above. The linear densities of each yarn which was collected from different open-end mills were given, and the level twists were recorded on the actual production of the machine. The properties of the fabric are measured as shown in Table 3, and in this regard, the thickness of the fabric varies because the imperfection of each yarn differs; in fact, it is possible to mention a lot of reasons; however, in this paper, the warp and weft density are similar for all fabrics regardless of other constraints [12].

All values of each fabric are summed, and the average is taken to see the relation of air permeability and imperfection in general: air permeability with respect to fabric cover (A), air permeability with respect to thick places $/ \mathrm{km}(\mathrm{B})$, air permeability with respect to thin places (C), and air permeability with respect to yarn neps (D). Usually, the relationship of the fabric cover with air permeability is reverse, meaning that if the fabric cover increases, the surface of the fabric is going to be more dense, and air cannot penetrate and pass through the entire of the fabric surface, and it leads to a decrease in the air permeability. However, this is not always true; air may be passing through the intrayarn or on the body of the yarn in addition to the porosity of the fabric which is the space that is not covered by warp and weft yarns, and the graph may not be linear as illustrated in Figure 4(a). Similarly, the imperfections (thick, thin, and neps) have no linear line with respect to air permeability because of the air may be pass through on the intrayarn body or of porosity which means that if the yarn has low twist, the air has an ability to pass through in the cross section of the yarn in addition to the unweave space between the two consecutive warp and weft yarns. Generally, based on the constant parameters and the performance of the yarn, the relationship between air permeability and the imperfection is not mostly linear as shown in Figures 4(b)-4(d).

3.1. Data Analysis. On the ANOVA, the factor level is two with one response which is analyzed in the design of the experiment, and in this paper, there are two approaches to know the significance of two levels of factors with respect to air permeability of the fabric. Those are neps $(+280 \%)$ and thick place $(+50 \%)$ as presented two levels of factors and fabric air permeability $\left(\mathrm{m}^{3} / \mathrm{m}^{2} / \mathrm{min} @ 100 \mathrm{~Pa}\right)$ as presented a response and used the quadratic model for fabric air permeability and the linear model for fabric cover as illustrated in Tables 4 and 5 based on the five statistical analysis tools which are sum of squares, $\mathrm{df}$, mean square, $F$-value, and $P$ value.

Table 4 shows that the model $F$-value of 13.74 implies the model is significant. There is only a $0.09 \%$ chance that an $F$ - 
TABLe 1: Experimental design for the test.

\begin{tabular}{|c|c|c|c|c|c|c|c|}
\hline Sample codes & & & & & Yarn parameters & & \\
\hline $\begin{array}{l}\text { Yarn Codes A, B, C, } \\
\text { D, and E }\end{array}$ & $\begin{array}{l}\mathrm{U} \\
\%\end{array}$ & $\begin{array}{c}\mathrm{CVm} \\
\%\end{array}$ & $\begin{array}{c}\text { Thin places/km } \\
(-50 \%)\end{array}$ & $\begin{array}{l}\text { Thick places } / \mathrm{km} \\
(+50 \%)\end{array}$ & $\begin{array}{l}\text { Neps/km } \\
(+280 \%)\end{array}$ & Hairiness & Breaking strength $(\mathrm{N})$ \\
\hline Number of tests & 20 & 20 & 20 & 20 & 20 & 20 & 10 \\
\hline $\begin{array}{l}\text { Fabric Codes A, B, } \\
C, D \text {, and E } \\
\text { Number of tests }\end{array}$ & & Fabric & $\begin{array}{l}\text { veight }\left(\mathrm{g} / \mathrm{m}^{2}\right) \\
10\end{array}$ & $\begin{array}{c}\text { Fabric thickness } \\
(\mathrm{mm}) \\
10\end{array}$ & $\begin{array}{c}\text { Fabric parameters } \\
\text { Warp density } \\
(\text { ends } / \mathrm{cm}) \\
10\end{array}$ & $\begin{array}{l}\text { Weft density } \\
\text { (picks/cm) } \\
10\end{array}$ & $\begin{array}{c}\text { Fabric air permeability }\left(\mathrm{m}^{3} /\right. \\
\left.\mathrm{m}^{2} / \mathrm{min} @ 100 \mathrm{~Pa}\right) \\
20\end{array}$ \\
\hline
\end{tabular}

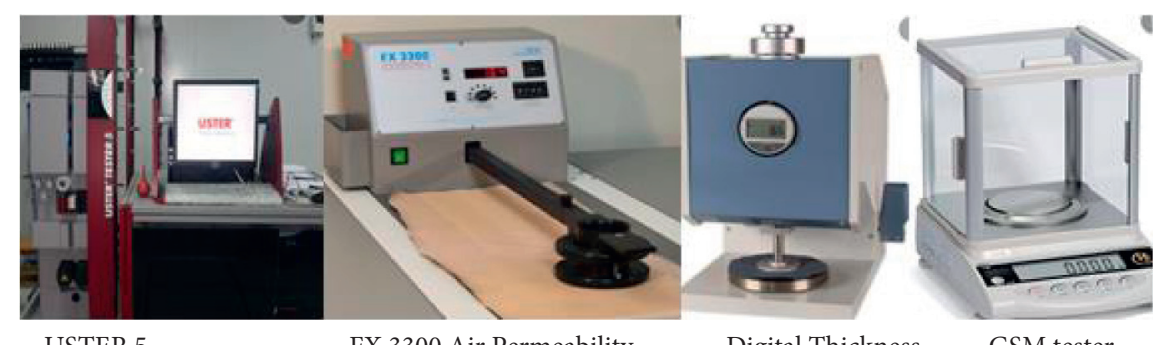

USTER 5

FX 3300 Air Permeability

Digital Thickness

GSM tester

FIGURE 3: Testing equipment.

TABLE 2: USTER statistics of yarn evenness.

\begin{tabular}{lcccccc}
\hline Types of yarn code & U\% & CVm\% & Thin places $/ \mathrm{km}(-50 \%)$ & Thick places $/ \mathrm{km}(+50 \%)$ & Neps $/ \mathrm{km}(+280 \%)$ & Hairiness \\
\hline Code A & 14.58 & 18.23 & 96 & 794 & 1125 \\
Code B & 15.91 & 19.89 & 100 & 902 & 1245 & 7.85 \\
Code C & 16.18 & 20.23 & 87 & 894 & 1421 \\
Code D & 14.31 & 17.89 & 91 & 889 & 1602 \\
Code E & 14.40 & 18.00 & 89 & 958 & 6.19 \\
\hline
\end{tabular}

TABle 3: Yarn and fabric properties.

\begin{tabular}{lcccccccccc}
\hline $\begin{array}{l}\text { Types } \\
\text { of yarn } \\
\text { code }\end{array}$ & $\begin{array}{c}\text { Yarn } \\
\text { linear } \\
\text { density } \\
(\mathrm{Ne})\end{array}$ & $\begin{array}{c}\text { Twist } \\
\text { per } \\
\text { meter } \\
(\mathrm{TPM})\end{array}$ & $\begin{array}{c}\text { Calculated } \\
\text { yarn } \\
\text { diameter } \\
(\mathrm{cm})\end{array}$ & $\begin{array}{c}\text { Breaking } \\
\text { strength } \\
(\mathrm{N})\end{array}$ & $\begin{array}{c}\text { Fabric } \\
\text { weight } \\
\left(\mathrm{g} / \mathrm{m}^{2}\right)\end{array}$ & $\begin{array}{c}\text { Fabric } \\
\text { thickness } \\
(\mathrm{mm})\end{array}$ & $\begin{array}{c}\text { Warp } \\
\text { density } \\
(\mathrm{ends} / \\
\mathrm{cm})\end{array}$ & $\begin{array}{c}\text { Weft } \\
\text { density } \\
(\text { picks/ } \\
\mathrm{cm})\end{array}$ & $\begin{array}{c}\text { Fabric air } \\
\text { permeability } \\
\left(\mathrm{m}^{3} / \mathrm{m}^{2} / \mathrm{min}\right. \\
100 \mathrm{~Pa})\end{array}$ & $\begin{array}{c}\text { Calculated } \\
\text { total fabric } \\
\text { cover }\end{array}$ \\
\hline Code A & 20 & 920 & 0.015 & 0.32 & 167 & 0.53 & 28 & 20 & 25.1 & 0.6172 \\
Code B & 20 & 902 & 0.017 & 0.26 & 161 & 0.49 & 28 & 20 & 28.3 & 0.5776 \\
Code C & 20 & 915 & 0.017 & 0.28 & 158 & 0.35 & 28 & 20 & 31.8 \\
Code D & 20 & 900 & 0.018 & 0.21 & 157 & 0.41 & 28 & 20 & 26.2 & 0.7098 \\
Code E & 20 & 911 & 0.019 & 0.29 & 160 & 0.51 & 28 & 20 & 24.1 & 0.6651 \\
\hline
\end{tabular}

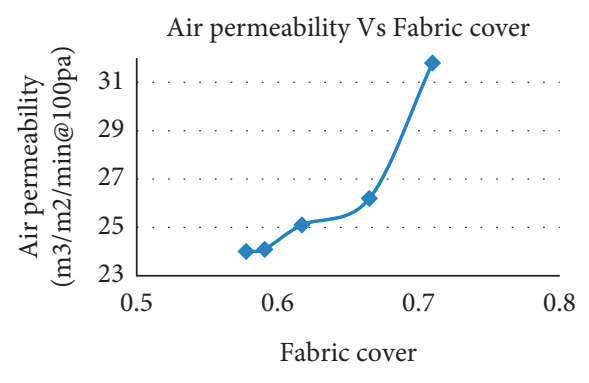

(a)

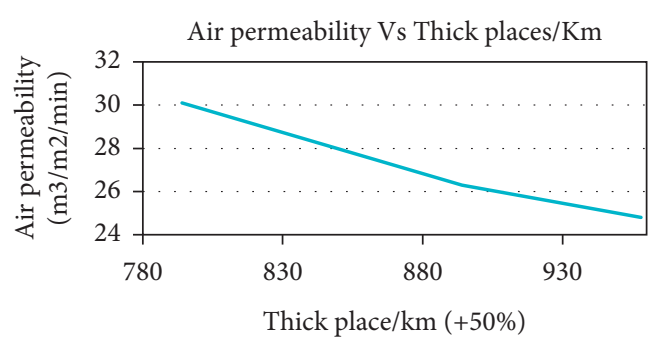

(b) 


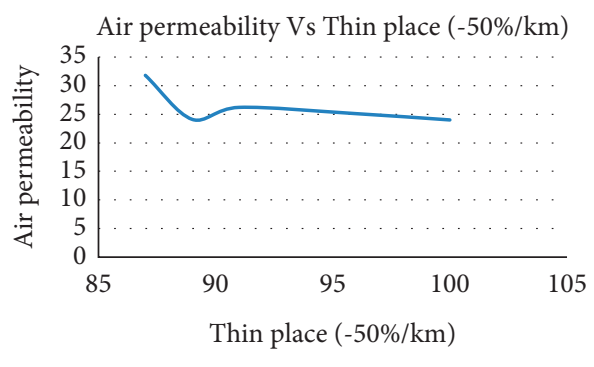

(c)

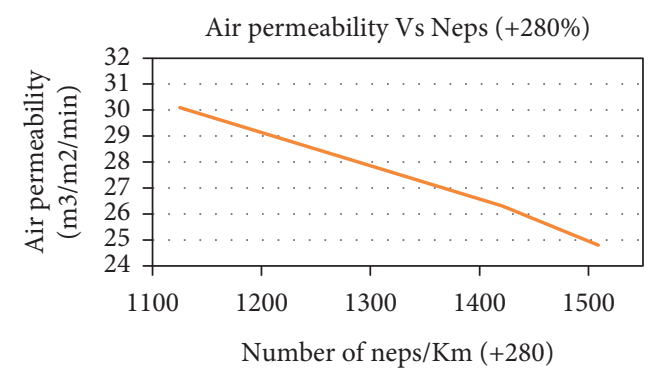

(d)

FIgURE 4: The relations of each imperfection on the air permeability of the fabric.

TABLE 4: Response 1: air permeability by using ANOVA for the quadratic model.

\begin{tabular}{lccccc}
\hline Source & Sum of squares & $\mathrm{df}$ & Mean square & $F$-value & $P$ value \\
\hline Model & 39.12 & 5 & 7.82 & 13.74 & 0.0009 \\
A-neps & 18.69 & 1 & 18.69 & 32.83 & 0.0004 \\
B-thick place & 13.38 & 1 & 13.38 & 23.50 & 0.0013 \\
$\mathrm{AB}$ & 0.2450 & 1 & 0.2450 & 0.4304 & 0.5302 \\
$\mathrm{~A}^{2}$ & 5.88 & 1 & 5.88 & 10.34 & 0.0123 \\
$\mathrm{~B}^{2}$ & 0.0199 & 1 & 0.0199 & 0.0350 & 0.8563 \\
Residual & 4.55 & 8 & 0.5693 & & 0.0015 \\
Lack of fit & 4.30 & 3 & 1.43 & 27.76 & Significant \\
Pure error & 0.2579 & 5 & 0.0516 & & \\
Cor total & 43.67 & 13 & & & \\
\hline
\end{tabular}

TABLE 5: Response 2: fabric cover by using ANOVA for the linear model.

\begin{tabular}{lccccc}
\hline Source & Sum of squares & df & Mean square & $F$-value & $P$ value \\
\hline Model & 0.0235 & 2 & 0.0117 & 15.44 & 0.0006 \\
A-neps & 0.0211 & 1 & 0.0211 & 27.72 & 0.0003 \\
B-thick place & 0.0024 & 1 & 0.0024 & 3.17 & 0.1025 \\
Residual & 0.0084 & 11 & 0.0008 & & 0.8886 \\
Lack of fit & 0.0024 & 6 & 0.0004 & 0.3411 & Not significant \\
Pure error & 0.0059 & 5 & 0.0012 & & \\
Cor total & 0.0319 & 13 & & & \\
\hline
\end{tabular}

value this large could occur, and the $P$ values less than 0.0500 indicate model terms are significant. In this case, neps and thick places of the yarn are significant model terms. In this regard, the number of neps and thick places on the surface of the yarn has a direct impact on the fabric air permeability. The regression model is used to generate response surface and contour plots of the tool life response. The response surface plot and the contour plot in terms of factors A (neps) and $B$ (thick place) with $C$ (air permeability) at the high level are shown in Figure 5. It shows the curvature due to the $A B$ interaction. These plots make it easy to see the region of greatest tool life of the response and as gradually increase the value of the factors which are the number of neps and thick place similarly the fabric air permeability is high. In fact, during the interlacement of two systems of yarns with high number of neps, thick and thin place are leads to construct open fabric due to the occurrence of porosity [13] between the two consecutive yarns regardless of the level of twist. In this plot, the blue color of the response showed that it has low permeability through the surface of the fabric, deep green showed that there is moderate air permeability at the intersection point of the two factors, and the last color is deep red which indicates that, as the number of imperfections increases on the surface of the yarn has to produce porosity between them and the fabric is high amount of volume air passed on the surface. Air can pass in two ways: firstly, on the core of the yarn, and secondly, on the porosity or the space between the two consecutive warp or weft yarns, but the first case mostly depends on the insertion of twist level on the strand of the material and the alignment and parallelism of individual fibers on the cross section of the yarn. In this paper, the second case is investigated based on the appearance of the yarn examined on the USTER statistics and analyzed by this plot.

The lack-of-fit $F$-value of 27.76 implies the lack of fit is significant. There is only a $0.15 \%$ chance that a lack-of-fit $F$ - 


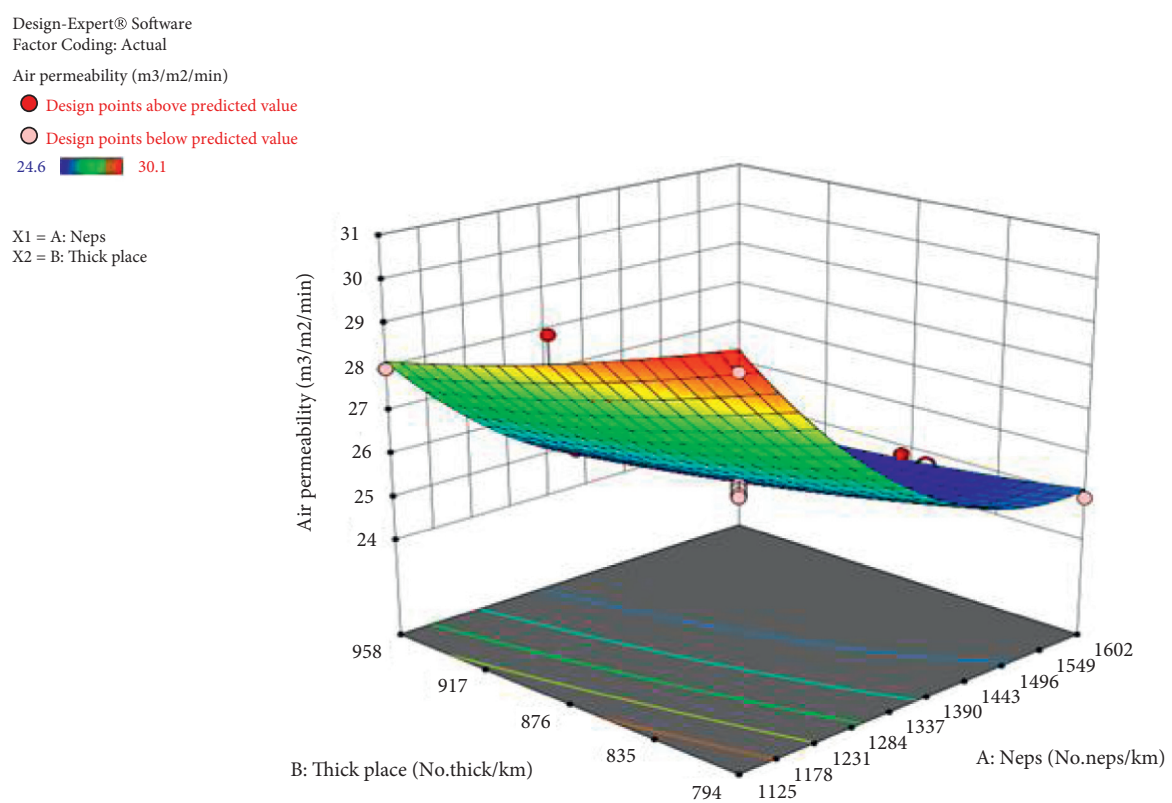

FIgURE 5: The regression model of the response with two factors.
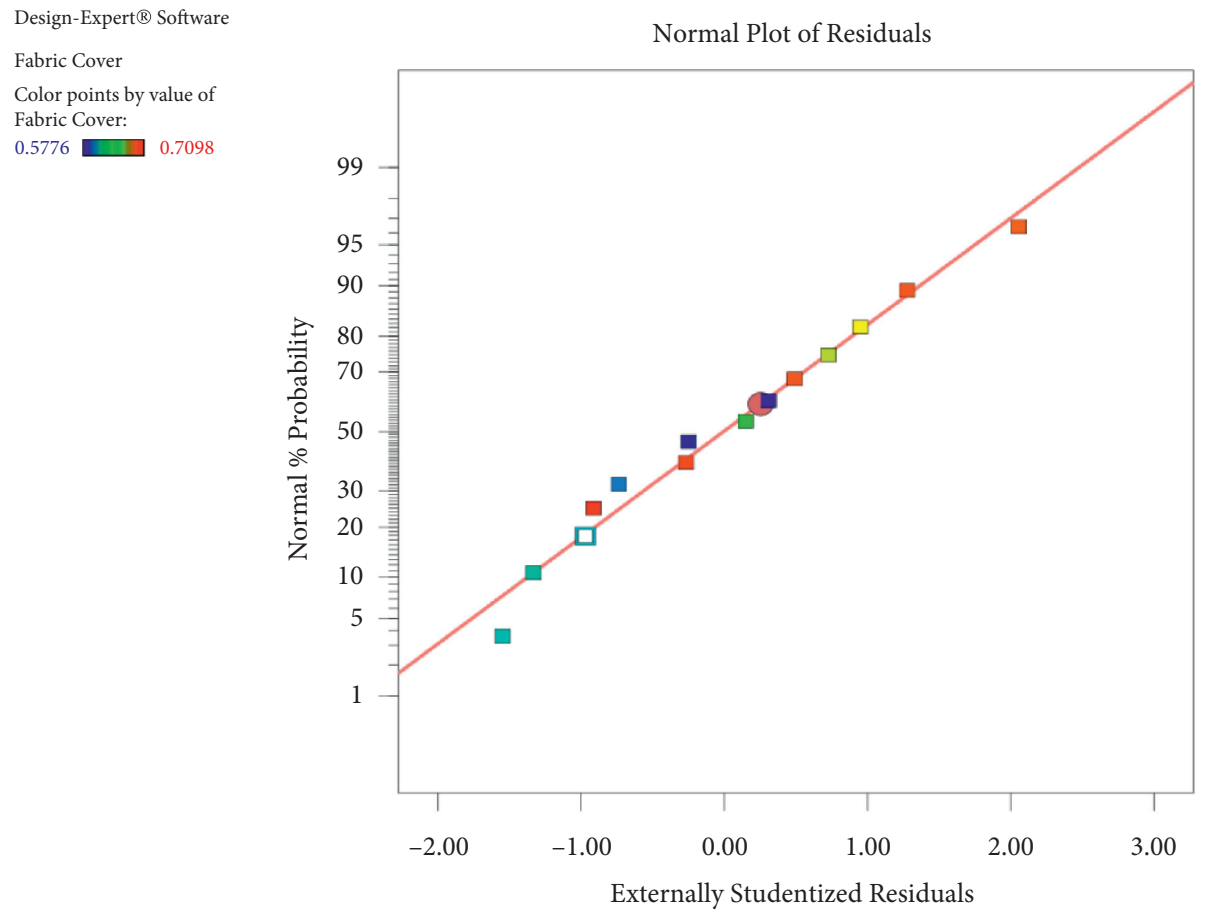

Figure 6: The normal plot of residuals.

value this large could occur. Significant lack of fit is bad and needs to change the model, but in this regard conceder only the selected parameters and it need to check the other properties of yarn and fabric. There are a lot of factors which affect the air permeability of fabrics.

Table 5 shows that the model $F$-value of 15.44 implies the model is significant. There is only a $0.06 \%$ chance that an $F$ value this large could occur, and $P$ values less than 0.0500 indicate model terms are significant. In this case, neps are a significant model term. Values greater than 0.1000 indicate the model terms are not significant. In this regard, the number of neps has a direct impact on the fabric cover, but the thick places on the surface of the yarn is not change or a direct impact on the fabric cover as shown in the model, in this situation it needs to see other parameters related to yarn properties and fabric cover unless otherwise if there is a thick 


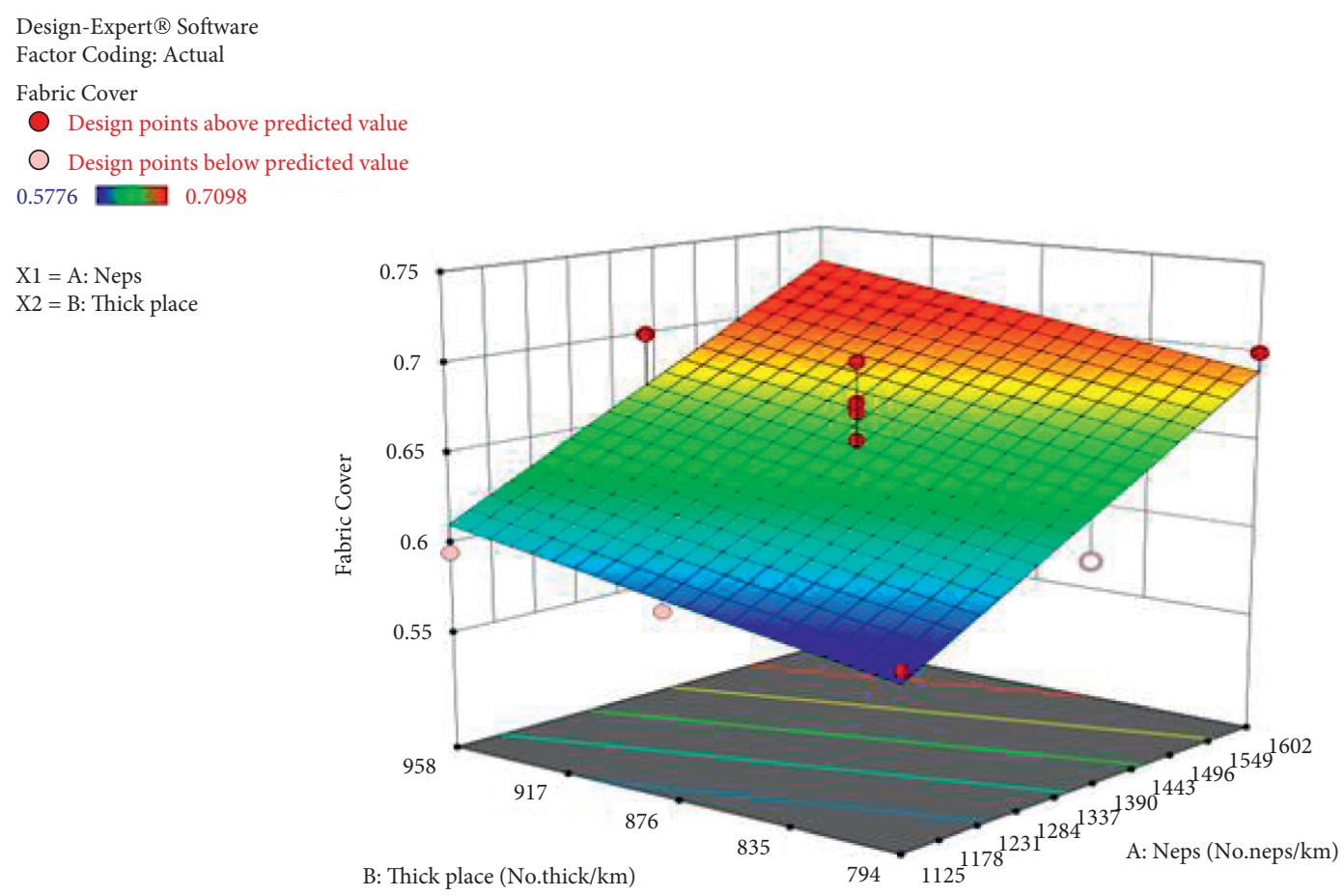

FIGURE 7: The regression model of the response with the two-factor level.

place on the yarn strand it leads to reduce the space between the two consecutive warp and weft yarns by regardless of twist and others.

On the normal probability plot, we are looking to see if the observations follow the given line. This tells us that the distribution of residuals is approximately normal as shown in Figure 6. Positive values for the residual (on the $y$-axis) mean the prediction was too low, and negative values mean the prediction was too high; 0 means the guess was exactly correct.

Figure 7 shows the linear regression model of the fabric cover within the factors of the number of neps and thick places. This model is significant meaning that there is an impact of factors on the response and the thick place and the number of neps accumulation are leads to a great contribute the coverage of yarn on the surface of the fabric with its porosity because those two imperfections are a thicker diameter of yarn with compare to the standard diameter. Always, the neps and thick places are higher in diameter than the normal cross section of the yarn.

\section{Conclusion}

In this experiment, the impacts of the imperfections (thin place $-50 \%$, thick place $+50 \%$, and neps $+280 \%$ ) on the air permeability of the fabric and fabric cover are discussed. In this paper, two approaches were used to know the significance of two levels of factors with respect to air permeability of the fabric and fabric cover. These are neps $(+280 \%)$ and thick places $(+50 \%)$ as presented two levels of factors and fabric air permeability $\left(\mathrm{m}^{3} / \mathrm{m}^{2} / \mathrm{min} @ 100 \mathrm{~Pa}\right)$ as presented a response and used the quadratic model for fabric air permeability and linear model for fabric cover. The values of the factors which are the number of neps and thick places increase the fabric air permeability which is high. In fact, during the interlacement of two systems of yarns with high number of neps, thick and thin place are leads to construct open fabric due to the occurrence of porosity between the two consecutive yarns regardless of the level of twist. Both regression models showed that all values are significant which means there is a direct impact of the two factors on the response regardless of some parameters.

\section{Data Availability}

Most of the data are organized based on the experimental outputs and some of literature studies.

\section{Conflicts of Interest}

The author declares no conflicts of interest.

\section{Acknowledgments}

The author would like to express their sincere gratitude to EiTEX (Ethiopian Institute of Textile and Fashion Technology) for providing the chance and funding to carry out this research work in laboratories under the Textile Production Research Center (TRIC).

\section{References}

[1] P. Kanakaraj, B. S. Dasaradan, and R. Ramachandran, "The influence of double layer knit fabric structures on air and water vapor permeability," Journal of Textile and Apparel, Technology and Management, vol. 8, pp. 1-9, 2013. 
[2] Yi Li, Sensory Comfort Fabric Transport Properties and Subjective Response during Exercise under Cool and Hot Environmental Conditions, JHKITA, 1997.

[3] M. Tàpias, M. Ralló, and J. Escofe, “Automatic measurements of partial cover factors and yarn diameters in fabrics using image processing," Textile Research Journal, vol. 82, pp. 1-14, 2010.

[4] V. Milašius, R. Milašius, E. Kumpikaité, A. Olšauskiené, and V. Milašius, "Influence of fabric structure on some technological and end-use properties," Fibres and Textiles in Eastern Europe, vol. 2, no. 41, pp. 48-51, 2003.

[5] L. Surdu, I.-R. Radulescu, C. Ghituleasa et al., "Comfort properties of multilayer textile materials for clothing," Industria Textila, vol. 64, no. 2, pp. 75-79, 2013.

[6] H. H. Epps, "Prediction of single layer fabric air permeability by statistical modeling," Journal of Testing and Evaluation JTEVA, vol. 24, no. 1, pp. 26-31, 1986.

[7] B. P. Saville, Physical Testing of TextilesWoodhead Publishing Limited, Cambridge, UK, 2003.

[8] A. Seyam and A. El-Shiekh, "Mechanics of woven fabrics, part III: critical review of weavability limit studies," Textile Research Journal, vol. 7, no. 63, pp. 371-378, 1993.

[9] M. Ta 'pias, M. Rallo', J. Escofet, I. Algava, and A. Riva, "Objective measure of woven fabric's cover factor by image processing," Textile Research Journal, vol. 80, pp. 35-44, 2010.

[10] W. Klein, Manual of Textile Technology, The Textile Institute, Manchester, UK, 1995.

[11] C. A. Lawrence, Fundamentals of Spun Yarn Technology, CRC Press LLC, Boca Raton, FL, USA, 2003.

[12] A. Çay, R. Atav, and K. Duran, "Effects of warp-weft density variation and fabric porosity of the cotton fabrics on their colour in reactive dyeing," Fibres and Textiles in Eastern Europe, vol. 15, pp. 91-94, 2007.

[13] A. V. Kulichenko and L. V. Langenhova, "The resistance to flow transmission of porous materials," Journal of the Textile Institute, vol. 83, no. 1, pp. 127-132, 1992. 